\title{
Unruptured Aneurysm at the Origin of the Duplicated Middle Cerebral Artery Treated by Coil Embolization: A Case Report
}

\author{
Shingo Toyota, Tetsuya Kumagai, Hirofumi Sugano, Shota Yamamoto, Kanji Mori, \\ Takuyu Taki \\ Department of Neurosurgery, Kansai Rosai Hospital, Amagasaki, Japan \\ Email: stshto@aol.com
}

Received 25 December 2014; accepted 10 January 2015; published 16 January 2015

Copyright (C) 2015 by authors and Scientific Research Publishing Inc.

This work is licensed under the Creative Commons Attribution International License (CC BY). http://creativecommons.org/licenses/by/4.0/

\section{(c) (i) Open Access}

\begin{abstract}
Aneurysm at the origin of a duplication of the middle cerebral artery (DMCA) is very rare, and only 29 treated cases have been reported. All of the cases were treated by direct surgery except a ruptured case treated by intentional partial coil embolization. We report the first unruptured case treated by coil embolization and review the previously published cases. Coil embolization can be alternative treatment for an unruptured aneurysm at the origin of the DMCA. Stable framing to spare the origin of it and prevention of thromboembolic complications are keys for safe treatment.
\end{abstract}

\section{Keywords}

\section{Duplicated Middle Cerebral Artery, Aneurysm, Coil Embolization}

\section{Introduction}

Aneurysm at the origin of a duplication of the middle cerebral artery (DMCA) from the internal carotid artery (ICA) is very rare, and only 29 treated cases (18 ruptured cases, 11 unruptured cases) have been reported [1][24]. All of the cases were treated by direct surgery except a ruptured case treated by intentional partial coil embolization. We report the first unruptured case treated by coil embolization and review the previously published cases.

\section{Case Report}

A 75-year-old woman presented with sudden headache (Hunt and Kosnik grade 2). CT scan showed diffuse 
subarachnoid hemorrhage (fisher group 3). Three-dimensional (3D) CT angiography demonstrated a right MCA aneurysm and a left ICA aneurysm. Because we diagnosed that the right middle cerebral artery (MCA) aneurysm had ruptured in the basis of the distribution of subarachnoid hematoma, neck clipping was performed via right pterional approach. We confirmed ruptured findings of the aneurysm during operation. The postoperative course was uneventful with no symptomatic vasospasm. She was discharged without neurological deficits.

Because she wished endovascular treatment of the left ICA unrupured aneurysm she was scheduled to undergo coil embolization of it. Before coil embolization, cerebral angiography was performed. It revealed that the aneurysm of $4 \mathrm{~mm}$ size was located between the origin of the posterior communicating artery and top of the ICA. 3D digital subtraction angiography (DSA) revealed that a DMCA which perfused the temporal lobe was originated from the aneurysm neck (Figure 1). It was also demonstrated that the AchA was originated from ICA.

Coil embolization was performed 2 months after the clipping surgery. The antiplatelet therapy with $100 \mathrm{mg}$ of aspirin and $75 \mathrm{mg}$ of clopidogrel was started 7 days before coil embolization. Under general anesthesia, heparin was administered systemically to maintain ACT above 200 seconds, and $6 \mathrm{~F}$ guiding catheter was introduced into the left ICA. Because the aneurysm neck was wide and DMCA was originated at the base of the aneurysm, coil embolization was performed with balloon remodeling technique. HyperGlide Balloon $(4 \mathrm{~mm} \times 10 \mathrm{~mm}$, ev3 Neurovascular, Irvine, CA, USA) was inserted and placed to cover the aneurysmal neck, and the tip of the microcatheter (SL-10; Stryker, Kalamazoo, MI, USA) was introduced into the aneurysmal dome. We inserted Presidio Microcoil (10 size, $4 \mathrm{~mm} \times 11.5 \mathrm{~cm}$, Codman Neuroendovascular. Johnson \& Johnson, Miami, FL, USA) as a flaming coil to spare the origin of the DMCA under the assistance of balloon remodeling technique (Figure 2). Thereafter, Target Detachable Coil (Stryker, Kalamazoo, MI, USA) of $2.5 \mathrm{~mm}$ and DELTAPLUSH Microcoil (Codman Neuroendovascular. Johnson \& Johnson, Miami, FL, USA) of $1.5 \mathrm{~mm}$ were embolized. Finally, almost complete occlusion of the aneurysm was obtained, and origin of the DMCA was spared to keep the patency of it (Figure 3).

She was discharged without neurological deficits. After coil embolization, antiplatelet therapy with $100 \mathrm{mg}$ of aspirin was continued for 3 months. 6 months after the treatment, cerebral angiography confirmed that stable occlusion of the aneurysm and patency of the DMCA.

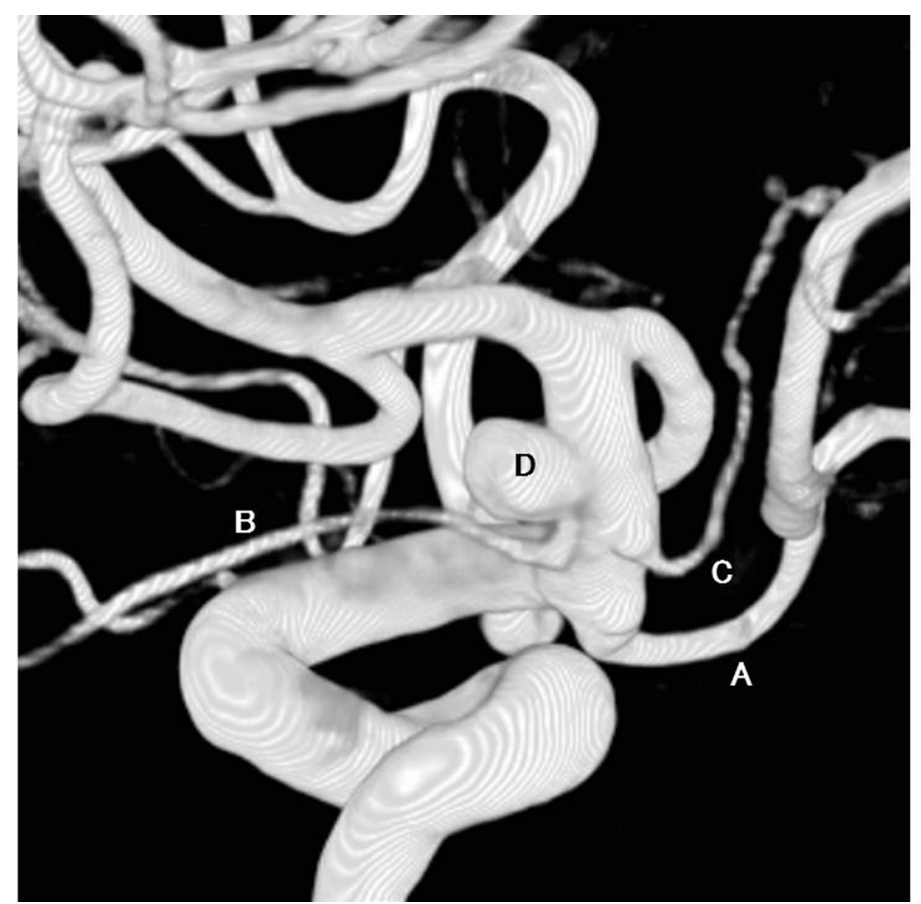

Figure 1. 3D digital subtraction angiography before coil embolization. The aneurysm was located between the origin of the posterior communicating artery (PcomA) and top of the ICA. Duplicated middle cerebral artery (DMCA) which perfused the temporal lobe was originated from the aneurysm neck. The anterior choroidal artery (AchA) was originated from ICA. A: PcomA; B: DMCA; C: AchA; D: Aneurysm. 


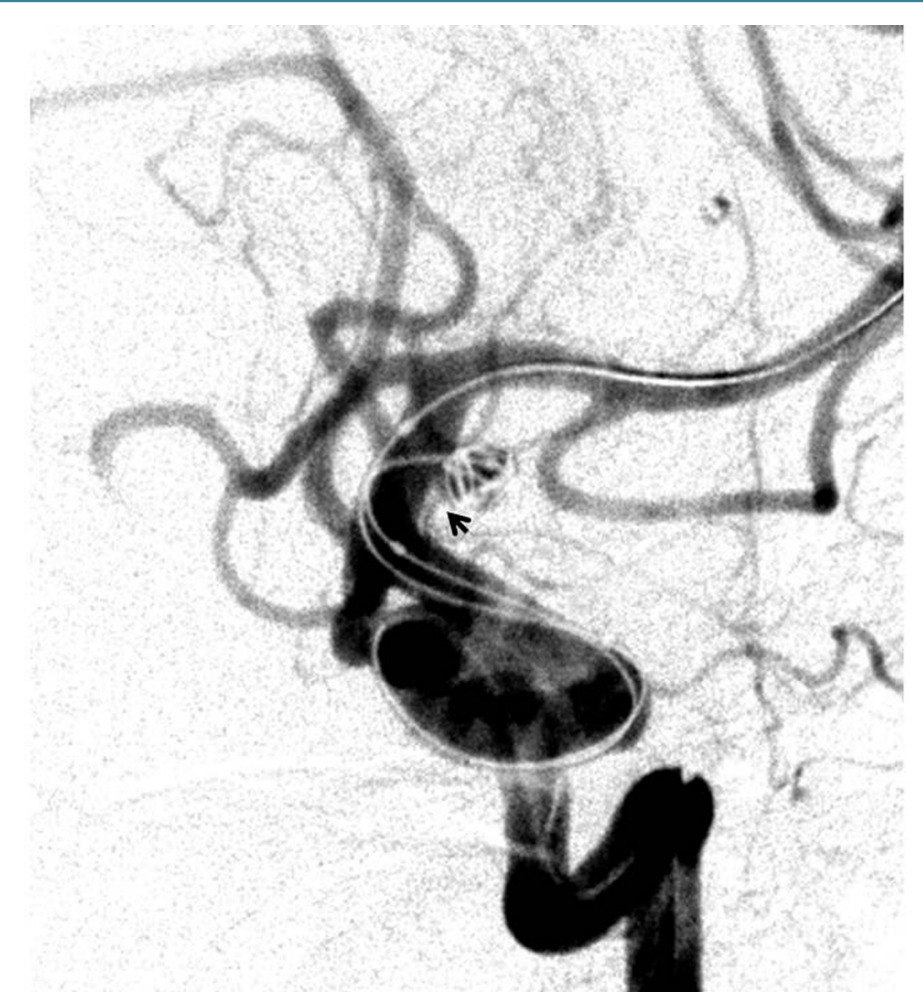

Figure 2. Angiogram during coil embolization. The framing coil was inserted to spare the origin of the DMCA under the assistance of balloon remodeling technique. Arrow: the origin of the DMCA.

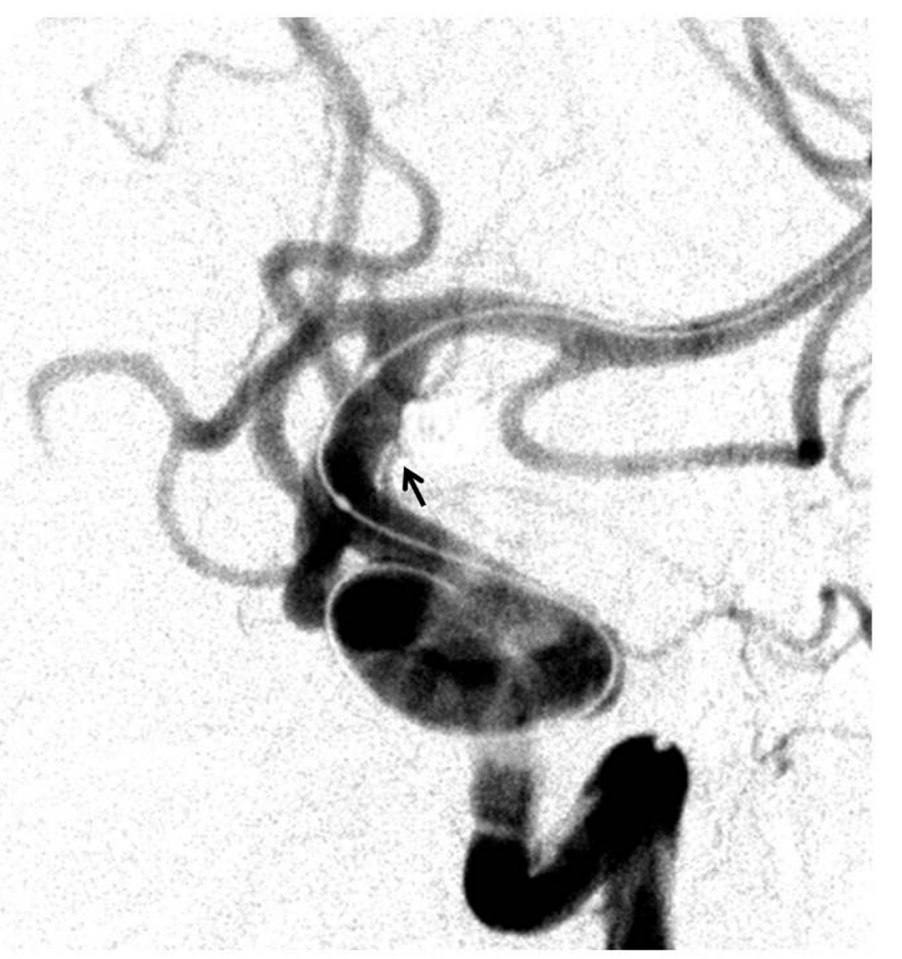

Figure 3. Angiogram just after coil embolization. Almost complete occlusion of the aneurysm was obtained, and origin of the DMCA was spared to keep the patency of it. Arrow: the origin of the DMCA. 


\section{Discussion}

Intracranial vascular anomalies involving the MCA are rare [25]. Teal et al. defined vessels that arose from the ICA between the anterior choroidal artery (AchA) and the terminal bifurcation of the internal carotid into the middle and anterior cerebral arteries as a "duplication of the MCA". In contrast, a vessel arising from the anterior cerebral artery (ACA) was defines as "accessory of the MCA" [26]. Both variations of the MCA are considered as persistent embryonic vessels. The incidence of DMCA is reported as $0.7 \%$ to $2.9 \%$ in autopsy cases [25]. This anomalous vessel is associated with various other intracranial anomalies such accessory MCA, azygos ACA, and moyamoya disease [5] [15]. However, the association of a cerebral aneurysm with this anomaly is very rare, and only 29 treated cases have been reported [1]-[24]. Komiyama et al. reported that the DMCAs supplied the cortical territory of the temporopolar and the anterior temporal and/or middle temporal arteries, and they had perforating arteries in three of four cases [27]. As the DMCA may contribute to the normal cerebral blood flow and it may play an important role in supplying collateral flow to the frontal lobe and the basal ganglia through the perforating arteries, sometimes the area of the AchA [16] [22] [27] [28], care should be taken not to damage this vessel during surgery.

We reviewed the previously published 29 treated cases of the aneurysms at the origin of the DMCA. Size of aneurysms was divided into 3 categories regarding maximum diameter: small (less than $10 \mathrm{~mm}$ ), large $(10 \mathrm{~mm}$ or more, less than $25 \mathrm{~mm}$ ), and giant (25 mm or more). Wide-necked aneurysm was defined as an aneurysm with a dome-to-neck ratio less than $2.0 \mathrm{and} /$ or a neck length of $4 \mathrm{~mm}$ or more with evaluation of angiographic findings of the published data. The cases whose necks could not be evaluated were excluded.

All of the 18 ruptured cases were treated by direct surgery except a case treated by intentional partial coil embolization. And all of the 11 unruptured cases were treated by direct surgery. Most of the aneurysms were small, except 2 large cases. There were no giant aneurysms. 20 of 25 cases whose necks could be evaluated were wide-necked aneurysms (Table 1). In most of them, the DMCAs originate at the base of the aneurysms. In some cases, the aneurysm arises solely from the DMCA rather than the junction of the internal carotid artery and the DMCA [4] [23] [24].

Because, in most of the aneurysms at the origin of the DMCA, the necks are wide and the DMCAs originate at the base of the aneurysms, direct surgery has some advantages for obliteration of the aneurysm with keeping the patency of DMCA. Therefore, all of the cases were treated by direct surgery except one case. Direct surgery has another merit to utilize bypass technique. Kai et al. performed superficial temporal artery (STA)-DMCA anastomosis before clipping of an aneurysm at the DMCA origin, because they found it difficult to separate the origin of the DMCA from the aneurysm dome because of dense adhesions [15]. LaBorde et al. also performed STA to distal MCA bypass before surgical trapping of a fusiform aneurysm at DMCA [23].

In coil embolization of the DMCA aneurysm, it is not easy to make a stable frame to spare the origin of DMCA because most of the aneurysms are wide-necked and the DMCAs originate at the base of the aneurysms. If the framing coil is unstable, coil embolization should be given up before detach of the first coil and direct surgery should be considered. Takahashi et al. reported kissing aneurysms, involving an ICA-DMCA, as well as an ICA-AchA, and manifesting as subarachnoid hemorrhage [21]. They employed simple technique and aimed for intentional partial embolization. Endovascular treatment was successfully performed with loose embolization at the aneurysm neck to spare the origin of the DMCA. But their strategy is not always secure from the viewpoints of the risks of recurrences or rebleeding after coil embolization. In present case, in order to spare the origin of the DMCA, Presidio was selected for the framing coil. Because the coil has strong memory function, it is possible to form box-shaped frames for wide-necked aneurysms. And additional coils can be inserted stably once after framing with Presidio because it is long enough to make a strong frame. Balloon remodeling technique was also utilized to spare the origin of the DMCA. To perform balloon remodeling technique safely, not only anticoagulant therapy during operation, but also antiplatet therapy in perioperative period were necessary. Another care should be taken in order not to damage the adjacent AchA by the tips of microcatheter or microguidewire because it is usually difficult to observe both origin of the DMCA and the AchA with one working angle simultaneously.

\section{Conclusion}

Our report is the first unruptured case of an aneurysm at the origin of the DMCA treated by coil embolization. Coil embolization can be alternative treatment for an unruptured aneurysm at the origin of the DMCA. Stable framing to spare the origin of it and prevention of thromboembolic complications are keys for safe treatment. 
Table 1. Summary of the treated cases of DMCA aneurysm. F, female; M, male; R, right; L, left.

\begin{tabular}{|c|c|c|c|c|c|c|c|c|}
\hline Case & Reference & Age & Sex & Side & Size & Neck & $\begin{array}{l}\text { Ruptured or } \\
\text { unruptured }\end{array}$ & $\begin{array}{l}\text { Direct surgery or } \\
\text { endovascular surgery }\end{array}$ \\
\hline 1 & Stabler & 31 & $\mathrm{~F}$ & $\mathrm{R}$ & Small & Wide & Ruptured & Direct surgery \\
\hline 2 & In et al. & 29 & $\mathrm{~F}$ & $\mathrm{R}$ & Small & Wide & Ruptured & Direct surgery \\
\hline 3 & Fuwa et al. & 46 & $\mathrm{~F}$ & $\mathrm{R}$ & Small & Unevaluable & Ruptured & Direct surgery \\
\hline 4 & Kobayashi et al. & 33 & $\mathrm{~F}$ & $\mathrm{R}$ & Small & Unevaluable & Ruptured & Direct surgery \\
\hline 5 & Kitami et al. & 46 & $\mathrm{~F}$ & $\mathrm{R}$ & Small & Wide & Ruptured & Direct surgery \\
\hline 6 & Kitami et al. & 60 & M & $\mathrm{R}$ & Small & Small & Ruptured & Direct surgery \\
\hline 7 & Takano et al. & 74 & M & $\mathrm{L}$ & Small & Wide & Unruptured & Direct surgery \\
\hline 8 & Dong et al. & 50 & M & $\mathrm{L}$ & Small & Wide & Ruptured & Direct surgery \\
\hline 9 & Takahashi et al. & 51 & $\mathrm{~F}$ & $\mathrm{~L}$ & Small & Unevaluable & Ruptured & Direct surgery \\
\hline 10 & Takahashi et al. & 54 & M & $\mathrm{L}$ & Small & Wide & Ruptured & Direct surgery \\
\hline 11 & Koyama et al. & 28 & M & $\mathrm{R}$ & Small & Wide & Ruptured & Direct surgery \\
\hline 12 & Nomura et al. & 63 & $\mathrm{~F}$ & $\mathrm{R}$ & Small & Wide & Unruptured & Direct surgery \\
\hline 13 & Kimura et al. & 83 & $\mathrm{~F}$ & $\mathrm{~L}$ & Small & Small & Ruptured & Direct surgery \\
\hline 14 & Tabuse et al. & 34 & $\mathrm{~F}$ & $\mathrm{R}$ & Small & Wide & Ruptured & Direct surgery \\
\hline 15 & Imaizumi et al. & 52 & M & $\mathrm{L}$ & Small & Wide & Unruptured & Direct surgery \\
\hline 16 & Hori et al. & 67 & M & $\mathrm{R}$ & Small & Unevaluable & Ruptured & Direct surgery \\
\hline 17 & Hori et al. & 49 & M & $\mathrm{L}$ & Small & Wide & Unruptured & Direct surgery \\
\hline 18 & Kai et al. & 63 & $\mathrm{~F}$ & $\mathrm{~L}$ & Small & Wide & Unruptured & Direct surgery \\
\hline 19 & Kaliaperumai et al. & 39 & $\mathrm{~F}$ & $\mathrm{~L}$ & Small & Wide & Ruptured & Direct surgery \\
\hline 20 & Mizokami et al. & 49 & $\mathrm{~F}$ & $\mathrm{~L}$ & Small & Wide & Ruptured & Direct surgery \\
\hline 21 & Miyahara et al. & 56 & $\mathrm{~F}$ & $\mathrm{R}$ & Small & Small & Unruptured & Direct surgery \\
\hline 22 & Miyahara et al. & 58 & M & $\mathrm{R}$ & Small & Small & Unruptured & Direct surgery \\
\hline 23 & Kimura et al. & 60 & $\mathrm{~F}$ & $\mathrm{~L}$ & Small & Wide & Unruptured & Direct surgery \\
\hline 24 & Otani et al. & 66 & $\mathrm{~F}$ & $\mathrm{R}$ & Small & Wide & Ruptured & Direct surgery \\
\hline 25 & Elsharkawy et al. & 62 & M & $\mathrm{L}$ & Large & Small & Unruptured & Direct surgery \\
\hline 26 & Elsharkawy et al. & 55 & $\mathrm{~F}$ & $\mathrm{~L}$ & Small & Wide & Ruptured & Direct surgery \\
\hline 27 & LaBorde et al. & 34 & M & $\mathrm{L}$ & Large & Wide & Unruptured & Direct surgery \\
\hline 28 & Rennert et al. & 52 & $\mathrm{~F}$ & $\mathrm{~L}$ & Small & Wide & Unruptured & Direct surgery \\
\hline 29 & Takahashi et al. & 62 & $\mathrm{~F}$ & $\mathrm{~L}$ & Small & Wide & Ruptured & Endovascular surgery \\
\hline 30 & Present case & 75 & $\mathrm{~F}$ & $\mathrm{~L}$ & Small & Wide & Unruptured & Endovascular surgery \\
\hline
\end{tabular}

\section{Disclosure}

The authors report no conflict of interest concerning the materials or methods used in this study or the findings specified in this paper. We have no source or support on this study.

\section{References}

[1] Stabler, J. (1970) Two Cases of Accessory Middle Cerebral Artery, including One with an Aneurysm at Its Origin. British Journal of Radiology, 43, 314-318. http://dx.doi.org/10.1259/0007-1285-43-509-314 
[2] In, S., In, K., Kusano, N., Mizuki, H., Miyagi, J. and Kuramoto, S. (1981) A Case of Duplication of the Middle Cerebral Artery with Ruptured Aneurysm on Its Origin during Pregnancy (Author's Transl). No Shinkei Geka, 9, 337-341.

[3] Fuwa, I., Matsukado, Y. and Wada, H. (1984) Intracranial Aneurysms Associated with the Accessory Middle Cerebral Artery and Duplication of the Middle Cerebral Artery. Report of Two Cases. Neurologia Medico-Chirurgica (Tokyo), 24, 207-211. http://dx.doi.org/10.2176/nmc.24.207

[4] Kobayashi, H., Hayashi, T., Ootani, I. and Yoshida, Y. (1984) A Case of Duplication of the Middle Cerebral Artery Associated with an Aneurysm at Its Origin. St. Marianna Medical Journal, 12, 462-466.

[5] Kitami, K., Kamiyama, H. and Yasui, N. (1985) Angiographic Analysis of the Middle Cerebral Artery in Cerebral Aneurysms-Its Branching Pattern and So-Called Vascular Anomalies. No Shinkei Geka, 13, 283-290.

[6] Takano, S., Nose, T., Oowada, T., Shirai, S. and Maki, Y. (1988) Aneurysm Arising from Duplicated Middle Cerebral Artery. Case Report. Neurologia Medico-Chirurgica (Tokyo), 28, 910-914. http://dx.doi.org/10.2176/nmc.28.910

[7] Dong, L.W., Yamada, K., Ohta, T. and Takahashi, N. (1991) Ruptured Intracranial Aneurysm Combined with Multiple Cerebral Vessel Anomalies; a Case Report. No Shinkei Geka, 19, 975-978.

[8] Takahashi, T., Suzuki, S., Ohkuma, H. and Iwabuchi, T. (1994) Aneurysm at a Duplication of the Middle Cerebral Artery. American Journal of Neuroradiology, 15, 1166-1168.

[9] Koyama, S., Kotani, A., Sasaki, J., Tazoe, M. and Tsubokawa, T. (1995) Ruptured Aneurysm at the Origin of Duplication of the Middle Cerebral Artery-Case Report. Neurologia Medico-Chirurgica (Tokyo), 35, 671-673. http://dx.doi.org/10.2176/nmc.35.671

[10] Kimura, T. and Furuya, T. (2000) Three Cases with Duplication of the Middle Cerebral Artery. Surgery for Cerebral Stroke, 28, 45-50. http://dx.doi.org/10.2335/scs1987.28.1_45

[11] Nomura, M., Yamashima, T., Kita, D., Kida, S., Kajinami, K. and Yamashita, J. (2000) Duplication of the Middle Cerebral Artery Associated with an Unruptured Aneurysm. Acta Neurochirurgica, 142, 221-222. http://dx.doi.org/10.1007/s007010050029

[12] Imaizumi, S., Onuma, T., Motohashi, O., Kameyama, M. and Ishii, K. (2002) Unruptured Carotid-Duplicated Middle Cerebral Artery Aneurysm: Case Report. Surgical Neurology, 58, 322-324. http://dx.doi.org/10.1016/S0090-3019(02)00887-X

[13] Tabuse, M., Wakamoto, H., Miyazaki, H. and Ishiyama, N. (2002) The Usefulness of 3D-CTA for the Diagnosis of a Ruptured Aneurysm at the Origin of the Duplicated Middle Cerebral Artery: Case Report. No Shinkei Geka, 30, 327 331.

[14] Hori, E., Kurosaki, K., Matsumura, N., Yamatani, K., Kusunose, M., Kuwayama, N. and Endo, S. (2005) Multiple Aneurysms Arising from the Origin of a Duplication of the Middle Cerebral Artery. Journal of Clinical Neuroscience, 12, 812-815. http://dx.doi.org/10.1016/j.jocn.2004.08.033

[15] Kai, Y., Hamada, J., Morioka, M., Yano, S., Kudo, M. and Kuratsu, J. (2006) Treatment of Unruptured Duplicated Middle Cerebral Artery Aneurysm: Case Report. Surgical Neurology, 65, 190-193. http://dx.doi.org/10.1016/j.surneu.2005.05.032

[16] Kaliaperumal, C., Jain, N., McKinstry, C.S. and Choudhari, K.A. (2007) Carotid “Trifurcation” Aneurysm: Surgical Anatomy and Management. Clinical Neurology and Neurosurgery, 109, 538-540. http://dx.doi.org/10.1016/j.clineuro.2007.04.006

[17] Mizokami, K., Miyajima, Y., Koizumi, H., Endo, M., Kitahara, T., Yamada, M. and Fujii, K. (2008) A Case of Ruptured Internal Carotid Duplication of Middle Cerebral Artery Aneurysm. Current Practice of Neurosurgery, 17, 746751.

[18] Miyahara, K., Fujitsu, K., Ichikawa, T., Mukaihara, S., Okada, T. and Kaku, S. (2009) Unruptured Saccular Aneurysm at the Origin of the Duplicated Middle Cerebral Artery: Reports of Two Cases and Review of the Literature. No Shinkei Geka, 37, 1241-1245.

[19] Kimura, T. and Morita, A. (2010) Treatment of Unruptured Aneurysm of Duplication of the Middle Cerebral ArteryCase Report. Neurologia Medico-Chirurgica, 50, 124-126. http://dx.doi.org/10.2176/nmc.50.124

[20] Otani, N., Nawashiro, H., Tsuzuki, N., Osada, H., Suzuki, T., Shima, K. and Nakai, K. (2010) A Ruptured Internal Carotid Artery Aneurysm Located at the Origin of the Duplicated Middle Cerebral Artery Associated with Accessory Middle Cerebral Artery and Middle Cerebral Artery Aplasia. Surgical Neurology International, 1, 51.

[21] Takahashi, C., Kubo, M., Okamoto, S., Matsumura, N., Horie, Y., Hayashi, N., Kuwayama, N. and Endo, S. (2011) "Kissing" Aneurysms of the Internal Carotid Artery Treated by Coil Embolization. Neurologia Medico-Chirurgica, 51, 653-656. http://dx.doi.org/10.2176/nmc.51.653

[22] Elsharkawy, A., Ishii, K., Niemela, M., Kivisaari, R., Lehto, H. and Hernesniemi, J. (2012) Management of Aneurysms at the Origin of Duplicated Middle Cerebral Artery: Series of Four Patients with Review of the Literature. World Neurosurgery, $\mathbf{8 0}$, e313-e318. 
[23] LaBorde, D.V., Mason, A.M., Riley, J., Dion, J.E. and Barrow, D.L. (2012) Aneurysm of a Duplicate Middle Cerebral Artery. World Neurosurgery, 77, e201-e204. http://dx.doi.org/10.1016/j.wneu.2011.03.038

[24] Rennert, J., Ullrich, W.O. and Schuierer, G. (2012) A Rare Case of Supraclinoid Internal Carotid Artery (ICA) Fenestration in Combination with Duplication of the Middle Cerebral Artery (MCA) Originating from the ICA Fenestration and an Associated Aneurysm. Clinical Neuroradiology, 23, 133-136. http://dx.doi.org/10.1007/s00062-011-0120-3

[25] Crompton, M.R. (1962) The Pathology of Ruptured Middle-Cerebral Aneurysms with Special Reference to the Differences between the Sexes. The Lancet, 2, 421-425. http://dx.doi.org/10.1016/S0140-6736(62)90281-7

[26] Teal, J.S., Rumbaugh, C.L., Bergeron, R.T. and Segall, H.D. (1973) Anomalies of the Middle Cerebral Artery: Accessory Artery, Duplication, and Early Bifurcation. The American Journal of Roentgenology, Radium Therapy and Nuclear Medicine, 118, 567-575. http://dx.doi.org/10.2214/ajr.118.3.567

[27] Komiyama, M., Nakajima, H., Nishikawa, M. and Yasui, T. (1998) Middle Cerebral Artery Variations: Duplicated and Accessory Arteries. American Journal of Neuroradiology, 19, 45-49.

[28] Uchino, M., Kitajima, S., Sakata, Y., Honda, M. and Shibata, I. (2004) Ruptured Aneurysm at a Duplicated Middle Cerebral Artery with Accessory Middle Cerebral Artery. Acta Neurochirurgica, 146, 1373-1374. http://dx.doi.org/10.1007/s00701-004-0353-x 
Scientific Research Publishing (SCIRP) is one of the largest Open Access journal publishers. It is currently publishing more than 200 open access, online, peer-reviewed journals covering a wide range of academic disciplines. SCIRP serves the worldwide academic communities and contributes to the progress and application of science with its publication.

Other selected journals from SCIRP are listed as below. Submit your manuscript to us via either submit@scirp.org or Online Submission Portal.
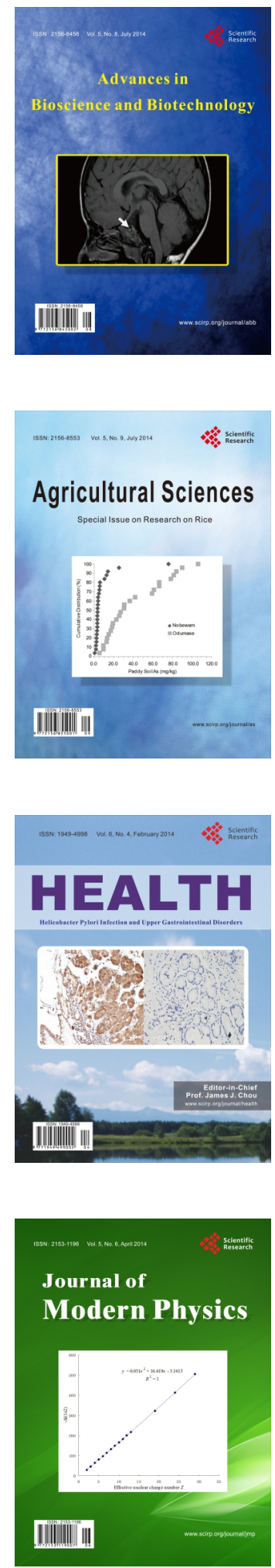
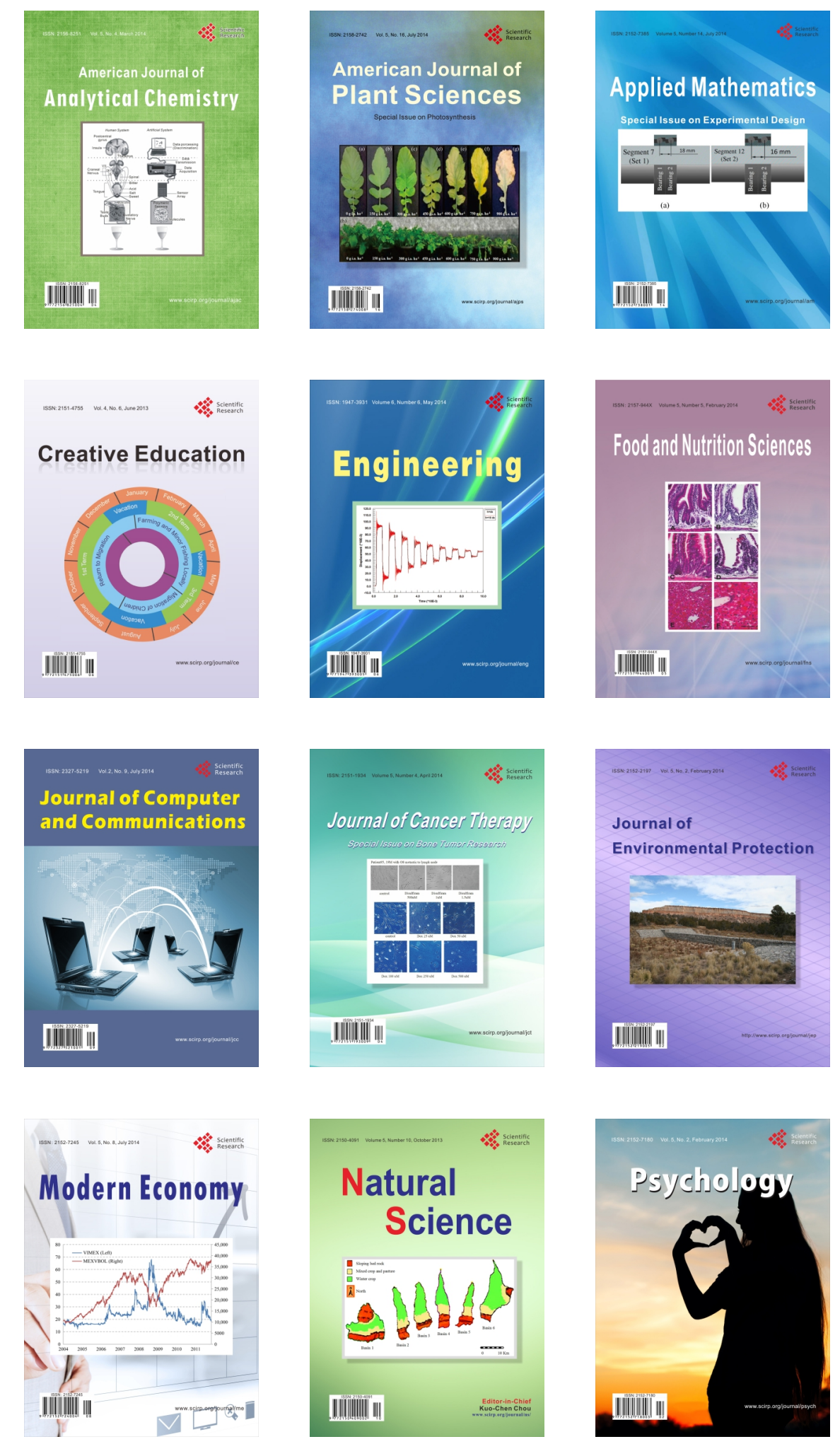